\title{
Para ver entre las sombras: la mirada de Albert Camus
}

\section{Looking through the shadows: the regard of Albert Camus}

\author{
LUCIANO EsPINOSA RUBio
}

Universidad de Salamanca

«La carne, la pobre carne, miserable, sucia, caída, humillada. La carne sagrada» (A. Camus, Cuaderno IX, 23-3-1959)

Resumen. Hay algunas personas libres que tienen algo semejante a una brújula, por eso en tiempos oscuros necesitamos lo que Albert Camus ofrece: un ejemplo vivo (no una lista de respuestas) de integridad, compasión y buen juicio. Tuvo que elegir (quizá como todos) entre el absurdo y la rebeldía, y después entre una actitud cotidiana de miedo o confianza. Finalmente, Camus nos dice que la naturaleza del ser humano y la belleza del mundo deben equilibrar las ambiciones históricas.

Palabras clave: juicio, ser humano, naturaleza, historia, absurdo, rebelión

\section{La urgencia del buen juicio}

Recabar la ayuda de Camus no implica efectuar una transposición directa de sus ideas, obviamente destinadas a otra época, sino seguir un talante y una forma de mirar, una actitud que anuda lo intelectual y lo ético de manera admirable: necesitamos aprender de alguien que unió en tiempos atribulados lucidez, belleza y compasión. Tampoco se busca un modelo perfecto - no es el santo laico que algunos pretenden y que él aborrecería
AbSTRACT. There are some free persons that have something like a magnetic needle, so in a dark time we need what Albert Camus offers: a living example (not a list of answers) of integrity, compassion and wise judgment. $\mathrm{He}$ had to choose (maybe like everybody) between nonsense and rebelliousness, and after between a daily attitude of fear or confidence. Finally, Camus tells us that the nature of human being and the beauty of the world must balance the historical ambitions.

Key words: judgment, human being, nature, history, nonsense, rebelliousness

ser - ni la respuesta definitiva a nada, pero le creemos cuando dice: «Vivir en y por la verdad. La verdad de lo que uno es, primeramente. Renunciar a componendas con los seres. La verdad de lo que es. No usar ardides con la realidad (...) La verdad es el único poder, alegre, inagotable. Si fuéramos capaces de vivir sólo de y por la verdad: energía joven e inmortal en nosotros». ${ }^{1}$ En la fecha tardía de 1958, después de tantos sinsabores y desengaños, el autor confirma este propósito de abrirse sin trampas a lo real, 
reconocerse como uno es y gozar de la fuerza que tiene el que no huye.

Porque ahí se ventila mucho más que una cuestión epistemológica al uso, que podría despacharse diciendo que es ingenuo aspirar a la verdad y más aún prescindir de las innumerables mediaciones que nos circundan y condicionan. Por el contrario, se trata de una experiencia ya sentida de entrega y receptividad sin engaños, de la alegría un tanto salvaje que proporciona el contacto franco con el mundo, participando de su misma energía inagotable. Por eso la verdad, de acuerdo con diversas tradiciones sapienciales, siempre va unida a la libertad y ambas fundamentan el oficio de escribir (o de crear en general), como resumió el escritor en el discurso de recepción del Nóbel en 1957 (V-166). La verdad se presentaría como una certeza íntima, en absoluto complaciente, que disuelve las ataduras y las hipotecas personales para generar una vida creativa, esto es, la expresión del sí mismo que fluye con el conjunto de las cosas y trata de mostrarlas con la mayor honestidad. Camus no era un místico, pero había aprendido a contemplar desde su infancia argelina - a la luz arrasadora del sol y también de la pobreza - la desnudez sustancial de las cosas (El revés y el derecho, I$14 \mathrm{~s}$.), como si el contacto con la naturaleza (en vez de la historia) y el despojamiento material le ayudaran a ser más penetrante.

Pero vayamos despacio, baste decir por ahora que esta pesquisa se ocupa de alguien que no condesciende a la simulación permanente, en el doble sentido de no querer fingir y de no aceptar sucedáneos (hoy serían simulacros tecnológicos) respecto a eso que llamamos el mundo y la vida. Alguien que se equivocó menos que otros porque tuvo la sensibilidad y el instinto certero para traspasar las tinieblas de los dogmatismos, siempre ahítos de coartadas, y además se distinguió por un compromiso insobornable a favor de la dignidad humana. Ahora bien, su planteamiento originario reconoce una herida con la que lidiar: hay una asimetría esencial entre mundo y hombre que genera desolación, lejos de la armonía y la paz anheladas, pero Camus se aferra a ambos con «piedad y reconocimiento», con los ojos abiertos tanto a la luz como a la muerte y, finalmente, con la única sabiduría del «Vivid como si...» (El revés...I-65 s). El escritor lo abraza todo (hombre y mundo, luz y muerte), pues cada miembro de la pareja es imprescindible y los dos están unidos entre sí justamente por el conflicto (conforme al dictado de Heráclito) que los afirma y niega en alternancia sin fin. El principio moral basado en la piedad y el reconocimiento permite vivir «como si» hubiera sentido y reconciliación posible en una realidad que ha empezado así a valer la pena. Tales son algunas de las claves previas que habrá que llenar de contenidos.

Visto desde otra perspectiva no menor, el francés supo mancharse las manos cuando y como era debido, cosa nada fácil en un contexto histórico cuajado de engaños y soflamas. Nunca fue la paloma ilusa y biempensante que los halcones quisieran caricaturizar -ayer y hoy - para desactivar al intelectual irreductible, sino más bien un profundo escéptico respecto a las ideologías en general, crítico tanto con el fanatismo idealista como con la degeneración en realismo pragmático y cínico. Camus denuncia sin ambages las actitudes nihilistas ocultas allí donde el fin justifica los medios, amén de reprocharles a aquellas supuestas cosmovisiones su incapacidad explicativa respecto a la vida humana y su perversa impotencia para dar cauce a la libertad. Hay un evidente trasfondo kantiano cuando afirma que el hombre 
nunca debe tomarse como un instrumento en aras de objetivos políticos, económicos, religiosos, etc., sino que son éstos los que deberían servir a su cuidado y respeto. Además, sin ser filósofo profesional — valga el oxímoron-supo atar y desatar bastantes nudos intelectuales de su época, es decir, pensar los nexos transversales y por tanto ejercer el logos, que es ante todo el pensamiento que relaciona y discierne. Dicho con otras palabras, intervino con criterio y ponderación desde el interior de los problemas, de ahí que nos importe un estilo personal de vida pero también su buen juicio y la posición humanista desde la que lo ejerce. ${ }^{2}$ Nunca bastan las buenas intenciones sin una mente esclarecida por la inteligencia y la bondad, donde lo importante es la alianza que refuerza a las dos.

Nuestras crisis actuales (económicas y morales, geopolíticas y ecológicas) tal vez parezcan menos definidas por falta de perspectiva histórica que las que él vivió (los totalitarismos de distinto signo, la II Guerra Mundial y la de Argelia, el mundo bipolar de la guerra fría...), pero no parecen menos graves: el cambio climático amenaza la vida tal como la conocemos, la desigualdad crece provocada por un economicismo depredador y especulativo sin límites, hay una falta de gobernanza global, la xenofobia se extiende, etc., y el resultado es la deshumanización de las conciencias por medios acaso más disimulados pero igual de insidiosos que antaño. Haya o no ciertas constantes en la desdicha de los hombres, puede decirse que hoy no faltan grandes dosis de extranjería metafísica y de peste material y moral: lo primero consiste en una mezcla de miedo, indiferencia, desorientación y frivolidad, además de una peculiar pérdida de contacto con la fisicidad del mundo (fenómenos en parte favorecidos por una tecnología sin control); y lo segundo incluye los lla- mados megapeligros de tipo nuclear, ecológico, financiero, etc. (Ulrich Beck dixit), así como una fragmentación excesiva del sentido y los fundamentalismos que pretenden compensarlo. A buen seguro que nuestro autor tendría mucho que decir sobre esta dispersión extrema de los espíritus y la consiguiente huida hacia delante de toda una civilización; o contra lo que podría denominarse la naturalización del capitalismo entendido ya como realidad atemporal, de manera análoga a como plantó cara al historicismo que justificaba la barbarie en aras de un futuro feliz (ambas son formas al fin y al cabo de ontologizar los errores); amén de rechazar la llamada desmaterialización tecnológica de la existencia que nos aleja del entorno y de los otros, haciendo imposibles los sentimientos de pertenencia y arraigo que siempre reivindicó el trasterrado pied noir.

Por eso necesitamos hacer memoria y establecer nuevas relaciones que ayuden a comprender el presente, narrar lo que acontece sin tonos mesiánicos ni apocalípticos, con la humanidad que él desplegó, de la mano de esa lucidez que le hizo percibir la vorágine del tiempo $a$ tiempo de no verse arrastrado por ella... pero sin escapar de él: «No soy un filósofo, en efecto, y no sé hablar sino de lo que he vivido. Viví el nihilismo, la contradicción, la violencia y el vértigo de la destrucción. Pero al mismo tiempo, celebré el poder de crear y el honor de vivir. Nada me autoriza a juzgar desde lo alto a una época de la que soy totalmente solidario. La juzgo desde el interior, confundiéndome con ella» (Crónicas 19481953, III-406). Con la humildad del que evoluciona para aprender y con la pasión del que vive con intensidad, el escritor es una voz autorizada que recuerda cosas fundamentales a menudo olvidadas, tales como el respeto profundo hacia la naturaleza que nos nutre y hacia el ser huma- 
no que es su más alta expresión, en tanto realidades que no pueden someterse al albur de los poderes de la historia so pena de catástrofe. En este sentido, $\mathrm{Ca}$ mus reivindica ciertos derechos naturales que considera inviolables y ajenos al capricho para utilizarlos como criterio regulador de lo bueno y lo malo. No se trata de ningún designio superior o externo a la decisión humana que lo instituye, por lo que puede asimilarse esa postura a la salvaguarda de lo que hay de sagrado en el hombre: la dimensión intangible que se contrapone siempre a lo que es utilitario y calculable porque reconoce «desde dentro» el destino mortal de todos, a la vez que se enfrenta sin desfallecer contra el imperio de lo necesario ${ }^{3}$. Nuestro escritor, en fin, suscribiría de buen grado pero sin fatuidad el adagio que reza «Homo homini deus».

Por otro lado, Camus encuentra en los resortes dramáticos y líricos de la literatura el mejor modo de no reducir la existencia a categorías formales, pragmáticas o técnicas, toda vez que aquéllos permiten fijarse mejor en la unicidad de cada uno de los seres y convertirlos en guía para no perder el rumbo moral ante las fuertes corrientes de la historia. Esa solidaridad profunda le hizo inmune al cinismo y a la grandilocuencia, dado que ambas cosas resultan incompatibles con un espíritu que procura no generalizar o esconderse en la abstracción administrativa. Pronto tuvo claro que el juego gratuito del mundo, así como la vanidad y el absurdo que lo acompañan, requieren el contrapeso de la lucidez, la perseverancia y la bondad, es decir, «En el fondo: los valores heroicos», según escribe en 1936 (Carnets I, I- 458). Este es el temple necesario, épico y trágico de consuno, para poner a las personas por delante de las ideas, del poder y del lucro. Camus fue consecuente con ello en tiempos de gran oscuridad, según la famosa expresión de $\mathrm{H}$. Arendt, de ahí la importancia que su buen juicio ético y político tiene como ejemplo vivo de la capacidad que los mejores teóricos sociales pedían ${ }^{4}$. Y es que, más allá de tal o cual opinión y circunstancia concretas, hay personas que tienen una especie de brújula interior que nunca pierde el norte. Él pagó con generosidad esa independencia de criterio, escuchó a su corazón sin sensiblería porque quería entender antes que juzgar, a la vez que esperaba sin esperanza... pero por encima de todo defendió al débil y al oprimido. Luego requerimos su magisterio (aunque haya cosas que solo responden a la intransferible intuición personal), destilando lo que conserve un mayor significado y de acuerdo al siguiente esquema: primero hay que conocer la posición desde la que vive y piensa, después su concepción general del mundo y al cabo la intención emancipadora que le mueve.

\section{El absurdo y la rebelión}

Para muchos, la humanidad parece estar suicidándose a cámara lenta, entre otras cosas porque la asimetría entre hombre y mundo comentada (la ausencia de sentido, el sufrimiento gratuito...) no sólo tiene un cariz metafísico sino ahora también físico y ecológico (los graves problemas medioambientales y climáticos, la desigualdad, etc.), amén de verse atrapados en una maraña de complejidad inmanejable y desbordante debida a la llamada globalización. Lo peor es que, a pesar de esta tremenda crisis de conjunto, priman todavía la inconsciencia e incluso la frivolidad al respecto, sin que los nuevos peligros planetarios merezcan la atención precisa, por lo que hay doble motivo para preocuparse. Es fácil sentirse abrumado cuando a la amenaza nuclear no desaparecida se suman este tipo de riesgos, lo que en cierto modo corro- 
bora por vía empírica la primigenia desolación mentada antes en un plano metafísico. Sea como fuere, la pregunta por la postura última ante la vida que cada uno debe tomar sigue pendiente, al margen de ser optimista o pesimista y de las coyunturas particulares.

2.1. La respuesta de Camus es que el mundo está gobernado por un «azar insensato» que hace imposible el ansia de unidad y absoluto, pero, en lugar de rehuir ese absurdo o caer en el resentimiento, hay que afrontarlo y entender que la vida gana fuerza con la inocencia que otorga la falta de un orden ontológico y moral predeterminado; de donde a su vez nace la posibilidad de rebelarse contra el dolor: «una de las únicas posiciones filosóficas coherentes es, por tanto, la rebelión. Es una confrontación perpetua del hombre con su propia oscuridad. Es exigencia de una transparencia imposible (...) No es aspiración, pues carece de esperanza. Esta rebelión es la seguridad de un destino aplastante, menos la resignación que debería acompañarla (...) Esta rebelión da su precio a la vida. Extendida a lo largo de toda una existencia, le restituye su grandeza. Para el hombre sin anteojeras no hay espectáculo más bello que el de la inteligencia en lucha con una realidad que la supera. El espectáculo del orgullo humano es inigualable» (El mito de Sísifo, I-258 s.). Digamos que hay coraje y placer estético en esta primera forma de rebeldía frente a la adversidad y las propias limitaciones del hombre, lo cual le dignifica y basta para llenar de contenido a la vida. Tanto más si ello es fruto de la propia libertad que rechaza el suicidio y decide entrar de lleno en las posibilidades que la existencia ofrece, una vez asumido que todos comparten la misma condición básica y están llamados por tanto a solidarizarse entre sí.
Uno no se rebela contra la hipotética injusticia del mundo - que es amoral-, sino contra la resignación a la «oscuridad» y contra quienes se valen de ella para someter y explotar. Ahora bien, semejante opción tiene algo de inexplicable, no nos engañemos, pues nada se espera ni hay pauta de conducta fijada, de modo que es el acto mismo de rebelarse el que funda cualquier valor y propósito ulteriores. Al final siempre hay que hacer una apuesta, en el mejor estilo pascaliano, especialmente si parece que la rebelión misma es absurda (en el límite de la paradoja), de modo que cada cual genera con ella un pequeño ámbito de sentido y asume la responsabilidad de compartirlo con los demás, sin falsas ilusiones... El escritor no deja lugar a dudas cuando efectúa el tránsito desde el enfoque general hacia la praxis: "Y llevando hasta su término esta lógica absurda, debo reconocer que esta lucha supone la ausencia total de esperanza (que nada tiene que ver con la desesperación), el rechazo continuo (que no se debe confundir con la renunciación) y la insatisfacción consciente (que no se debería confundir tampoco con la inquietud juvenil)» (ibid., I-239 s.). Luego nadie debe tergiversar esta actitud madura de desengaño, tan distante de la utopía (donde el futuro ahogaría al presente, quiera o no) como del desprecio hacia la realidad efectiva (a pesar de ser con frecuencia ingrata). Por el contrario, una vez más se niega y afirma a la vez, con los matices necesarios para abandonar la perenne «voluntad de ceguera» ${ }^{5}$ pero sin dejar de pedir algo mejor, aunque sepamos que no hay designio ni final feliz que valga.

Sencillamente, la persona lúcida promueve un mundo un poco más humanizado que no se destruya a sí mismo ni sea tan injusto, una vez que instaura un significado en el acto mismo de la rebe- 
lión y descubre la dignidad que eso encierra para todos. Rebelarse es por tanto una forma de afirmación universal, en contra de lo que pudiera parecer, que pone en primer plano lo mejor de la existencia. Y se entra así en el terreno del más noble posibilismo: «Se trata de estar al servicio de la dignidad del hombre por medios que permanezcan dignos, en medio de un contorno histórico que no lo es. Mídase la dificultad y la paradoja de tal empresa. / Sabemos, en efecto, que la salvación del hombre es quizá imposible, pero afirmamos que eso no es una razón para dejar de intentarla y afirmamos sobre todo que no es lícito llamarla imposible antes de haber hecho, de una vez para siempre, todo lo necesario para demostrar que no lo era» (Crónicas 19441948, II-651). Dado el paso ético esencial recién mencionado, no caben excusas para la indiferencia y el derrotismo aun en las peores circunstancias, pues manda el compromiso también político de ayudar a otros. Por lo demás, la dignidad de los fines y de los medios van de la mano, claro está, desde el imperativo de hacer lo humanamente posible para evitar la perdición...o al menos de conferirle valor.

No cabe rendirse y si uno es derrotado en el intento tampoco significa darse por vencido, tal es la exigencia heroica ante la que nos encontramos. Lo de menos aquí es adoptar una posición retórica determinada, ni siquiera deciden las convicciones personales sobre asuntos particulares, sino la entrega (crítica y confiada a la par) en favor de la vida humana y eso obliga a sumergirse en la historia para combatir sus desmanes. Bajo este punto de vista, el éxito no consiste en alcanzar una meta final, sino en guiarse por un enfoque ateleológico que se aferra a los grados de alegría compartida por quienes no quieren ni pueden lavarse las manos ante el sufrimiento evitable. Las urgencias del mundo exigen que nadie se paralice en la desesperanza o el fatalismo, ése es un lujo que no podemos permitirnos - parece decir el francés-, como tampoco sirve de mucho la mera estética del perdedor. Más bien se trataría de mantener la calma en la tormenta en lugar de dejarse arrastrar por el pánico, como suele ocurrir - y sobran muestras actuales - cuando sacrificamos la libertad en el altar de una supuesta seguridad. Las sociedades sedicentemente democráticas parecen tentadas por una suerte de nostalgia agresiva que se aproxima cada vez más a las respuestas mitológicas y totalitarias de un pasado no tan lejano. En una palabra, hay que aguantar a la intemperie metafísica e histórica, pero lejos de adoptar un talante sacrificial lo que importa es el gozo de vivir como se ha elegido: sin tutelas y con generosidad.

2.2. Contribuir a ello requiere el esfuerzo de muchos, entre otros los intelectuales que tanto se han equivocado en su papel de rey-filósofo ejercido por vía interpuesta. En concreto, la filosofía ha cobrado en el pensamiento contemporáneo tintes proféticos y policiales que la han alejado de la «benevolencia», afirma el autor, pues las dos grandes formas del nihilismo contemporáneo - la burguesa y la revolucionaria - han sido lanzadas por intelectuales. Y por eso es urgente que éstos rectifiquen su actitud: primero reconociendo el daño y denunciándolo allí donde esté, después confesando su ignorancia en muchos aspectos y, por último, negándose a dominar y rechazando cualquier tipo de despotismo, incluso provisional (Crónicas 1948-1953, III390). No parece que fuera fácil encajar y asumir semejantes críticas en un mundo entonces polarizado y además rebosante de vanidades. Son conocidos los duros ataques que sufrió Camus por gran parte de la inteligencia de su tiempo, especial- 
mente del lado de la izquierda comunista, y no hace falta insistir en ello, pero ya es un tópico decir que el paso del tiempo le ha dado la razón al menos en lo esencial. ${ }^{6}$ Por lo demás, su crítica a los dos espectros ideológicos no implica equidistancia ni abstracta conciliación de los antagonismos, sino un ejercicio de libertad personal que consiste en evaluar cada caso político por sí mismo, desde el convencimiento de que el sectarismo siempre pierde los argumentos que pudiera tener para acabar haciendo el juego a la general opresión deshumanizadora. Apenas hace falta recordar que cada día es más necesaria esa actitud, como ampliaremos en el siguiente apartado.

Los dos nihilismos citados son anverso y reverso de la misma aniquilación de lo humano, si bien el modelo burgués aparece más difuso y amable en las formas, mientras que el revolucionario (hoy casi agotado) ha sido brusco y violento allí donde logró el poder. Algunos dirán que esa dicotomía se ha superado décadas después con el derrumbamiento soviético o el llamado «fin de las ideologías», así como con el imperio pragmático de la economía y en menor medida con el triunfo retórico de una democracia más que imperfecta, pero hay motivos para temer que el juego de la dominación no haya cambiado tanto. Quizá lo que ocurre es que ahora se desenvuelve detrás del escenario, sin tantas señas de identidad ideológica a la vista, a la par que aumenta la desigualdad entre los que tienen y los desposeídos en sentido material y simbólico. Por eso el intelectual, además de pedir perdón cuando corresponda por su soberbia cómplice, debería dar ejemplo hoy de actitud crítica y arriesgada, pues lo que antaño fue exceso de protagonismo ahora se ha tornado en ausencia interesada. Algo análogo, por cierto, a lo que ocurre con la política misma como organización institucional de la voluntad colectiva: no es que las instituciones dimitan de manera súbita frente a otros poderes (por ejemplo financieros), sino que hace mucho tiempo que cedieron el espacio público y el poder a los tecnócratas y a las corporaciones, de forma que estructuras esenciales de la sociedad son rehenes de múltiples intereses (económicos, burocráticos, clientelares, etc.), hasta el punto de que el sistema parece incapaz incluso de reformar mínimamente sus excesos y disfunciones. De ahí que, ante las incongruencias internas y la creciente desafección ciudadana, se haya denunciado que vivimos dentro de un marco de «legitimidades extraviadas» y de una descomposición social que busca contrapesar la situación apelando a una peligrosa «mundialización del comunitarismo» que desembocaría en un choque de ámbitos socio-culturales excluyentes, ${ }^{7}$ pasando por un resurgimiento nacionalista. Estos y otros asuntos urgentes reclaman la existencia de una raza de pensadores en la estela camusiana, los que mantienen la actitud de compromiso cívico desde la humildad y la firmeza, contrarios al miedo y al rechazo generalizados (primero de tipo geopolítico y ahora económico), aunque los intelectuales tengan menos peso específico que en el pasado y estén diluidos en un mundo hipertecnológico y lleno de ruidos.

A pesar de que las protestas contra la corrupción de toda clase aumenten, no habrá resultados duraderos sin que la rebeldía sea explícita y esté bien articulada, en vez de ser ocasional, cínica o tácita. Luego su expresión ética e intelectual tiene que prolongarse enseguida en la política, recuperando el aliento que nos ocupa para rectificar el nihilismo de nuevo cuño en curso, sea éste más indiferente, asustado o pragmático en la superficie, pues todos coinciden en el fondo destructor. Y, según el francés, la rebel- 
día política adquiere un sesgo paradójico porque solo hay verdadero progreso cuando «un problema político queda reemplazado por un problema humano» (Crónicas argelinas 1939-1958, IV-510), es decir, cuando escapa a la razón de estado, a la burocracia o la mera estadística, en la medida en que primen las cuestiones reales que atañen a sujetos de carne y hueso. No estaría mal, por ejemplo, aplicar este enfoque personalizador a la hora de parar esa estafa que llamamos la Gran Recesión desde 2008 en adelante. Se objetará que esto es imposible en un mundo tan complejo y mercantilizado como el nuestro, además de ser peligroso por incluir una carga anti-institucional, como se ha dicho de los movimientos de indignados que recientemente han aparecido en diversos lugares del mundo. ${ }^{8}$ Pero la conducta de los poderes establecidos ha sido siempre la misma: advertir del posible caos que traerían los cambios, despersonalizarlo todo excepto los privilegios de las élites, subordinar los medios a los supuestos fines colectivos de la estabilidad, moverse en el ámbito macrológico de los ideales retóricos, de las necesidades o de las cifras (estamos inundados de macroeconomía como nunca), en vez de tocar tierra con una mirada microfísica dirigida a las exigencias y sufrimientos de las vidas particulares.

Es obvio que las instituciones democráticas deben ser respetadas pero siempre con la intención de mejorarlas, y que es ineludible una gestión que maneje los «grandes números» en todos los órdenes, dicho de modo breve, pero si no hay visión política y se olvida la libertad activa de los individuos concretos a los que sirven todo resulta trastocado. Así, indica Camus, testimoniar el derecho a la vida autónoma de cada sujeto, a la diferencia dentro de la unidad y al diálogo es la misión del intelectual, pues «la inteligen- cia no dejó jamás de luchar para afirmar contra las abstracciones de la historia lo que rebasa a toda historia: la carne, ya sea sufriente o dichosa» (Crónicas 19441948, II-785). Tal es de nuevo el ancla que impide la deriva y la referencia segura para no dejarse engañar, por eso lo que corresponde es introducir las «fuerzas de la naturaleza y de la amistad» frente a la nivelación administrativa: lo cualitativo frente a lo cuantitativo, el amor frente al espíritu de conquista, y si esto se considera vano e irrisorio poco importa, «nosotros estamos en el mundo para demostrar lo contrario» (ibid.). Al final, queda la llamada a la creación (artística e intelectual) como reverso y complemento de la política, pues, aunque sirva de poco a corto plazo, tiene al menos el valor probatorio de que hay alternativas vitales y eso sí cuenta a la larga. El espíritu genuino del rebelde no solo aparece encarnado en empresas inmediatas y más o menos rentables, sino en los ejemplos vivos de quienes no claudican nunca.

Sería la manera correcta de repolitizar la existencia, atendiendo a las personas y a lo menudo de su peripecia, por un lado, y aportando la contribución de verdad y belleza que cada uno sepa, por otro. En este sentido hay que recuperar la vieja concepción de la política como el arte de lo posible, con flexibilidad pero sin resignación, una vez convenido que su tarea es tan contingente y trágica como la vida misma, por lo que a menudo está abocada a perseguir el mal menor, esto es, a evitar tanto las distopías del pensamiento implacable que gira en torno al bien común sacralizado como las del pensamiento impecable ligado a la obtención de la justicia a toda costa. ${ }^{9}$ El ser humano que vive entre absolutos se ensoberbece antes o después y los utiliza para oprimir, como enseña la historia, cuando en realidad todos comparti- 
mos la condición perspectivista, falible y limitada de la finitud. Pero igualmente peligroso es el absurdo agazapado en lo pequeño, la molicie y el conformismo ante los asuntos sucesivos que llenan los días, la indiferencia o el dejar pasar cualquier cosa si es en dosis digeribles, al modo de un destino ineluctable, como si nada pudiera hacerse y fuera imposible toda alternativa.

Rebelarse, en fin, es combatir la necesidad o la resignación para retomar la conciencia de que hay una «naturaleza humana» de la que surge todo valor y promover la «solidaridad que nace de las cadenas», donde el círculo fecundo de rebelión y complicidad fraterna vence en alguna medida al absurdo: «El mal que experimentaba un solo hombre se convierte en una peste colectiva. En nuestra prueba cotidiana la rebelión desempeña el mismo papel que el cogito en el orden del pensamiento: es la primera evidencia. Pero esta evidencia saca al individuo de su soledad. Es un lugar común que funda en todos los hombres el primer valor. Yo me rebelo, luego somos» (El hombre rebelde, III-39, y antes 38 y 32 s.). Partimos de la igualdad (natural) de lo humano ante la peste metafísica del dolor y la muerte, acompañada casi siempre de dominación y mentira en un plano histórico, por lo que la rebelión abre un espacio intersubjetivo fundado en el mutuo reconocimiento que no se conforma con lo dado y busca emanciparse. De ahí que el fin nunca pueda justificar los medios y que haya límites que no se pueden rebasar so pena de perder esa humanidad inalienable, ${ }^{10}$ del mismo modo que no es lícito quedarse en la pasividad desmoralizada. Camus, además, rechaza la pose estetizante tan frecuente hoy y su discurso no cae en el existencialismo narcisista, sino que conduce a la asunción de la responsabilidad personal ante el orden histórico de las cosas que pretenda disolver o menoscabar esa naturaleza común.

\section{Sobre el miedo y la confianza}

En un segundo nivel, el absurdo y la rebeldía se traducen en dos formas básicas de concebir la vida que siguen en pugna. El miedo, en primer lugar, siempre implica zozobra, recelo, coacción y a menudo obediencia forzada, sin que haga falta insistir en el uso político y religioso de que ha sido objeto como herramienta de control social. Pero aquí interesa notar la presencia de un miedo específico del mundo contemporáneo, así como su raíz, alcance e implicaciones a la hora de teñirlo casi todo. Por otro lado, es obvio que la confianza expresa justo lo contrario de la inquietud y la insidia propias del temor, una suerte de serenidad que se sobrepone al malestar e incluso al espanto que puedan producir los hombres y el mundo. Quien confía sin ingenuidad se ha liberado en lo mayor de las coerciones, siente que no tiene nada que perder y se entrega a la experiencia dueño de sí, ajeno a los excesos simbólicos de corte totalitario o al sinsentido nihilista y por tanto a la enmienda a la totalidad que ambos pretenden.

3.1. Hagamos algunas consideraciones sobre lo primero al hilo de los textos que nos ocupan: el XVII fue el siglo de las matemáticas, el XviII el de la física, el XIX el de la biología y el Xx es el «siglo del miedo», causado en buena medida por una ciencia capaz de destruir la Tierra y además un tipo de miedo convertido en «técnica» harto poderosa (Crónicas 1944-1948, II-705). El caso es que la Modernidad ha dado saltos cualitativos a la hora de cumplir el adagio «saber es poder», hasta el punto de que las ventajas y las amenazas actuales son incomparables con otras épocas. A lo que podríamos añadir en el siglo XXI la ex- 
pansión masiva del nuevo trascendental informático-digital que multiplica aquella potencia transformadora a la vez que mediatiza todo conocimiento y acción, amén de la inusitada capacidad biotecnológica de manipular las entrañas de los individuos. La hipótesis que nos guía es que, por debajo de las evidentes diferencias con las décadas centrales del siglo $\mathrm{xx}$, hay motivos semejantes para temer la tecnificación del miedo, definida por el autor francés como un «terror» fundado en una serie de prácticas habituales: la incomunicación (no hay diálogo ni disposición a ser persuadidos), la «conspiración del silencio» de la mayoría de la población basada en la inseguridad y los intereses creados, el imperio de lo abstracto («el mundo de las oficinas y de las máquinas, de las ideas absolutas y del mesianismo sin matices»), el hecho de que los hombres son entregados a su sola condición de seres históricos, ajenos a la belleza y la amistad, e incapacitados para la reflexión pausada, inmersos como están en «un mundo donde se legitima el homicidio y donde la vida humana se considera una futilidad» (ibid. II-706 s.). ¿Cuánto han cambiado las cosas?

Es cierto que Camus escribe esas líneas en un período sumamente ideologizado y violento, recién acabada la guerra mundial, y que hoy tenemos mayor conciencia respecto a la defensa de los derechos humanos, pero no parece que el diagnóstico sobre las causas de fondo sea muy diferente. Basta recordar las nuevas tensiones y formas de autodestrucción, tales como una competitividad exacerbada que aumenta la perenne dificultad para la concordia, las profundas crisis económicas y ambientales, la sofisticación extraordinariamente abstracta de los estilos de vida tecnológicos, los nuevos grupos mesiánicos de cuño teológico-político (neocons, islamistas...), etc. El historicismo clásico de raíz hegeliana y marxista que denunciaba el escritor es ahora débil, sin duda, pero no otras variantes del nihilismo para las cuales el éxito en los fines sigue justificando todos los medios (ibid. II-710 s.); ni tampoco las sucesivas debacles y desengaños han extirpado la ideología del progreso y del crecimiento sin límites, amén de la reaparición de formas simbólicas de salvación sin fisuras y por fuerza enfrentadas... En una palabra, persisten los miedos principales, ocasionados tanto por un exceso de ímpetu teológico renacido como por un defecto de sentido en una existencia mecanizada, lo que da lugar respectivamente a tipos de vida demasiado calientes (agresivos) o demasiado fríos (anómicos), y hay motivos para creer que la crisis de civilización que padecemos generará una pésima mezcla. Veamos algunos antecedentes del proceso en marcha.

La crítica que Camus dirige al pensamiento moderno (al menos desde Rousseau) se centra en el tono cuasirreligioso que adopta a la hora de exaltar a la colectividad e identificarse con la hipostasiada razón universal (El hombre rebelde, III-146 s.). Una vez asentado, este discurso ofrece al menos dos grandes expresiones igual de peligrosas para la libertad individual: una muy ligada a la naturaleza y crítica reactiva de la civilización a la que siempre considera degenerada, y otra historicista que promete un futuro esplendoroso al precio que sea. Al margen del análisis genealógico que realiza, cercano en parte a la crítica de la Ilustración de la Escuela de Frankfurt, importa anotar su idea de que el pesimismo medieval respecto a la condición humana se transforma luego en un antropomorfismo desaforado (Feuerbach) de cariz teleológico, donde impera «una equívoca concepción del mundo que asigna únicamente a la historia la tarea de producir los valores y la verdad. Si 
nada se puede concebir claramente antes de que se manifieste la verdad al final de los tiempos, toda acción es arbitraria y a la postre se impone la fuerza», como bien muestra la frecuente justificación del crimen de Estado (ibid., III-180). Pero la novedad es que la reivindicación de lo natural que el francés propone como antídoto contra el mecanismo histórico triunfante no se hace en términos reaccionarios, sino que más bien se trata de equilibrar la balanza y poner un límite, de manera que aquella arbitrariedad constructivista se detenga ante los derechos fundamentales del hombre. Afirmación y negación variables de naturaleza e historia vuelven a actuar como contrapesos al servicio de la libertad.

El escritor añade que el rebelde tiene que volverse en contra del revolucionario, pues éste termina siendo «opresor o hereje» en función de su ortodoxia (lo que le diferencia también del existencialista que defiende la revolución), toda vez que la historia es condición necesaria pero no suficiente de la vida y que el valor de ésta no depende de aquélla, que solo es su «causa ocasional»: la naturaleza humana no tiene «absoluta plasticidad» ni se reduce al sentido del tiempo, de modo que la historia es un límite cierto del hombre pero «la afirmación de una naturaleza común a todos los hombres»» escapa a los designios del poder (ibid., III-290 s.). Tal es el dique necesario ante las ideologías que postularon el hombre nuevo y el paraíso en la tierra, utopía que hoy podría tener un carácter biotecnológico no menos amenazante. En todo caso, insiste Camus, es preciso afirmar la «unidad» de lo humano a partir de algo común dado, pero también entenderlo como creación rebelde de «lo que somos» frente a la idea de «totalidad» que desprecia todo valor previo para «producir lo que no somos» (ibid., 292 s.). Contra la utilización despótica de la dialécti- ca, hay una naturaleza humana de la que partir para ser desplegada en toda su riqueza emancipadora - también opuesta al «moralismo formal» de la sociedad burguesa-, aunque el ideal humanista sufra evidentes derrotas. Digamos que, curiosamente, el autor hace un peculiar uso de la célebre «negación determinada», ${ }^{11}$ de manera que la negación de lo recibido para seguir avanzando no sea absoluta sino que conserve lo básico y se reconozca deudora de alguna «regla, moral o metafísica», es decir, que respete el límite de la dignidad humana.

Lo nocivo, dicho con otro lenguaje, es un artificialismo sin medida al servicio del deseo insaciable que define la Modernidad y que hace desaparecer a la naturaleza como interlocutora de la cultura, reduciéndola a simple condición instrumental. Es la misma poiesis exacerbada del hombre que llega hasta el presente de la mano de una voluntad de poder que no se detiene ante nada, un poco más difuminada en sentido ideológico pero no menos engreída por su aparente omnipotencia tecnológica. ${ }^{12} \mathrm{La}$ diferencia es que lo que antes se iba a conseguir por medio de la política ahora lo traerá la ciencia, siempre al servicio de una ambición que ansía abarcarlo todo. Conviene repetir que esa grave falta de cuidado respecto a la esfera natural está en la base de la creciente problemática ecológica y que además hay base para temer la utilización futura de la ingeniería genética, dirigida por algunos hacia un posthumanismo que pretende nada menos que superar al hombre como especie. ${ }^{13}$ Pero aquí no se defiende una absurda vuelta a la naturaleza, pues resulta claro que cualquier definición de la misma depende de la libre decisión humana, sino que reivindicamos una especie de alianza entre el derecho a vivir y el de elegir. El valor sagrado de la carne reside en la vulnerabilidad que une a los 
mortales, así como en su capacidad inteligente para ser altruistas, dubitativos o risueños, pongamos por caso, luego nada puede ser más dañino que establecer jerarquías entre hombres de primera, de segunda, etc., sea por medios tecnológicos o políticos irreversibles que nunca estarían al alcance de todos. Sobre todo cuando lo que se proyecta son «superhombres» previo pago.

De vuelta a Camus, su ataque al nazismo y al orden biológico que consagra el privilegio del hombre superior en virtud de la raza y de la fuerza es concluyente, según expuso en las Cartas a un amigo alemán (1944). Ahí argumenta que la flaqueza inicial de una civilización perpleja y asustada se torna finalmente en el triunfo de la justicia (como el curso de la guerra mundial prueba) sobre el poder nazi victorioso al comienzo, porque la fortaleza no nace de la «embriaguez» nacionalista ni de la «desesperación» histórica sino de la profunda convicción moral que une a los hombres en el respeto a la vida. Y añade que, como crear sentido es una exigencia humana, «Este mundo tiene al menos la verdad del hombre y es misión nuestra dotarle de razones contra el propio destino (...) Me dirá usted con su sonrisa y su desdén: ¿Qué es salvar al hombre? Y lo grito con todo mi ser: no es mutilarlo y sí es posibilitar que se cumpla la justicia, que es el único en concebir» (Cartas..., II-609). No se trata solo de resistir al fascismo, autoproclamado azote de un mundo decadente merced a una violencia que se anunciaba regeneradora $-\mathrm{y}$ que a tantos sedujo, no se olvide-,${ }^{14} \mathrm{ni}$ de apelar a cierto sentimentalismo pacificador o a conceptos de justicia eterna, sino de ser combativos para que los propios hombres elaboren sus aspiraciones desde el ejercicio compartido de la libertad creadora. Por eso el nuevo punto decisivo es la afirmación prioritaria de la feli- cidad más allá del heroísmo (ibid., II610), con lo que Camus da un paso importante en su evolución espiritual para dejar atrás el tono épico del comienzo y rescatar en cambio la noción de una plenitud humana como horizonte irrenunciable, por lejos que esté. En resumen, se pasa de una actitud de resistencia negativa a otra de afirmación positiva. Tampoco hay que buscar un designio por arriba (providencia) ni por debajo (orden natural fijo), por detrás o delante (historia pasada o futura), pues el hombre es el único sentido posible del mundo a pesar de ser frágil e imperfecto, y cada uno debe dar un cauce particular a la naturaleza común. Tal es el desafío de todos.

Pero aquella voluntad de poder tiene muchos disfraces y recientemente se travistió de voluntad de placer para sobornar a sujetos en efecto ajenos a cualquier valor heroico, con el consiguiente abaratamiento de la noción de felicidad. Esto choca con cualquier modelo de excelencia y su aspiración ética a lo mejor, dentro de los límites que nos constituyen. Y junto a ese adormecimiento de la conciencia crítica, no hay que perder de vista que los peligros globales aludidos facilitarán eventualmente que el poder adopte de nuevo su cara más tiránica. De hecho, ahí están los conflictos ligados a la escasez de recursos en distintos lugares del planeta, el endurecimiento de las leyes de vigilancia y control, los recortes sociales y de libertades, la esclerosis democrática, etc. ${ }^{15} \mathrm{El}$ miedo sin duda está de vuelta, si es que alguna vez se fue, y la desorientación del buen juicio que produce también. El balance de ambas vías de control es que resulta fácil laminar o subsumir la existencia bajo pautas y dispositivos heterónomos, luego el recordatorio camusiano de que cada persona tiene carácter único, por extraordinarias que sean las circunstancias, adquiere aún más peso. Entiéndase que esta ética 
consiste en obedecer (ob-audire: escuchar) a lo más profundo de uno mismo para reconocer la humanidad que nos dignifica a todos y que ésa es la única $f e$ aquí comentada.

3.2. La confianza nace de ciertos impulsos subjetivos, pero también surge de la reflexión y es corolario de las convicciones que nos han ocupado. Frente al miedo, el odio y la impotencia, existe la alternativa de abandonarse a las cualidades de los demás y reposar en la belleza que hay en el mundo. Sin fatuo optimismo, al igual que tampoco la condición trágica de los hombres se reduce a lamentaciones, importa convocar esa fuerza inteligente que se abre camino a poco que la dejen. Dependemos unos de otros en mil aspectos de la convivencia y eso funda la idea misma de sociedad, pero además queremos confiar por encima de los intereses y las decepciones porque ello supone una gratificación imprescindible de la fraternidad.

Camus lo expresa de muchas maneras, pero es quizá en el teatro donde adquiere mayor vivacidad, por ejemplo en la obra El estado de sitio (1948). Ahí subraya cómo la extendida cobardía que condena al hombre a la soledad y al sometimiento no logra impedir que también surja una fuerza liberadora de lo más hondo, «una locura clara» que contra todo pronóstico - permite que el ejemplo de unos pocos consiga que la máquina de la opresión comience a chirriar, una vez que se zafan del miedo y del odio (II-261 s. y 273). Incluso donde no hay razones teóricas ni condiciones empíricas que permitan esperarlo, adviene una calidad secreta en algunas personas que agrietan el muro o muestran al menos que hay otras opciones con su ejemplo. En lo más oscuro, Camus siempre expresa su confianza en lo que podríamos denominar el factor humano, es decir, en la rebeldía y la bondad de los mejores que pueden despertar lo mismo en otros; sin que por ello este componente lírico (más que épico) anule el desgarramiento y la percepción de lo que siempre queda por hacer. Levantarse contra la tiranía - externa e internasolo es el primer paso de una labor sin fin, trenzada con sensibilidades diferentes y objetivos dispares, como bien muestran los diversos personajes de la obra. Lo que no tiene cabida en ese modelo solidario es el resentimiento y la venganza de los que antes estaban oprimidos porque, además de matar la nobleza lograda, serían el vehículo para recaer en una dominación de signo inverso. Por el contrario, hay que abandonar el juego ominoso del poder que humilla al vencido (aunque sea culpable) y mancha al que lo ejerce, pues supone un simple cambio de manos para las cadenas y la misma traición a todos.

Esta postura de fondo (que tantas críticas recibió por ser considerada blanda o utópica) es una advertencia constante de Camus contra la repetición de la actitud política sectaria y contra el revanchismo. Y ése es el espíritu que rige también su combate frontal contra la pena de muerte (Reflexiones sobre la guillotina, 1957) y en general el rechazo hacia todo maniqueísmo, como se aprecia bien en las tomas de posición durante los juicios de la postguerra y en los momentos sumamente delicados para él de la lucha por la independencia de Argelia. Lo que nos remite a un veredicto benévolo sobre la condición humana, basado en esa confianza última que nada tiene que ver con el buenismo, dado que el mal es un «obstáculo infranqueable. Pero es también un obstáculo real para el humanismo tradicional. La muerte de los niños expresa la arbitrariedad divina, pero el asesinato de los niños significa la arbitrariedad humana. Estamos acorralados entre dos arbitrariedades. Mi posición personal, hasta 
donde pueda defenderse, es considerar que si bien los hombres no son inocentes, son culpables tan sólo de ignorancia» (Crónicas 1944-1948, II-758). Podría decirse que las dimensiones cósmica y antropológica del mal se complementan, pero son de rango diferente: la primera es irremediable y se funda en la amoralidad del mundo, la segunda implica responsabilidad y admite grados. Parece haber además un intelectualismo moral subyacente, digno émulo de Sócrates, pero harto matizado porque el escritor no disimula la crueldad humana y pide cuentas cuando la ignorancia es culpable. El desconocimiento profundo al que se refiere como clave del mal arraiga en las limitaciones de una finitud asustada y ciega antes que malvada y agresiva sin más ${ }^{16}$, y aún así la primera obligación moral consiste en hacer un esfuerzo de introspección que descubra la humanidad común. Además, hablar de esta ignorancia (no solo ni fundamentalmente epistémica) de los hombres significa oponerse a la idea de una maldad intrínseca que serviría de coartada a los pesimistas antropológicos para reprimir sin medida. Camus, en fin, no justifica ni tolera la inacción cómplice, pero nunca los desprecia, si acaso muestra una paciencia crítica no carente de compasión.

Los defectos de los hombres son tan obvios, podríamos decir, que hablan por sí solos y lo que demandan es el grado de apoyo necesario para saber aminorarlos, al igual que las virtudes requieren ser ensalzadas para hacerlas crecer. Por eso el perdón sincero que damos a otro nos lo concedemos a nosotros mismos, una vez conscientes de nuestra connaturalidad, y eso despeja el camino para ofrecer lo mejor de cada uno. Quizá sea cierto el verso célebre de Borges, «no nos une el amor sino el espanto», o quizá haga falta un suplemento positivo y a ello se refiere el autor cuando dice del ser huma- no: «Su rebelión más instintiva, al mismo tiempo que afirma el valor, la dignidad común a todos, reivindica obstinadamente, para saciar con ella su hambre de unidad, una parte intacta de lo real cuyo nombre es la belleza. Se puede rechazar toda la historia y aceptar, no obstante, el mundo de las estrellas y del mar (...) Es indudable que la belleza no hace las revoluciones. Pero llega un día en que las revoluciones la necesitan. Su regla, que impugna lo real al mismo tiempo que le da su unidad, es también la de la rebelión» (El hombre rebelde, III-322 s.). Habría por tanto un oculto resorte para el inconformismo, una fuerza rebelde en el fondo de cada cual que solo espera la oportunidad de emerger. Y la belleza lo permite (afirmando y negando una vez más) porque rescata la naturaleza frente a la historia y se pone al servicio de la libertad (cita los ejemplos literarios de Shakespeare, Cervantes, Molière y Tolstói), mientras revoca con su sola presencia la infamia de lo establecido. Y añade el francés con perspicacia que tal es «el camino de una revolución verdaderamente realista», en contra de las creencias pragmáticas al uso, ya que solo una disposición espiritual — cabe glosarque esté a la altura de las necesidades últimas será capaz de transformar las cosas hasta donde sea posible hacerlo.

Sin duda resuena aquí la vieja idea de que el mundo solo es soportable estéticamente, como acuñó Nietzsche, pero Camus no se queda ahí y requiere un enfoque ético: la belleza es una forma de «dura fraternidad» que durante milenios ha aliviado a los hombres y a veces incluso los ha liberado de la esclavitud, una vez hermanada con la «voluntad de clarividencia» (Conferencia en Upsala, V-187 s.). Así, contra al riesgo de caer en algún tipo de pasivo romanticismo, el gozo de la belleza en su sentido genuino es un afecto lúcido y movilizador que 
confirma la unión última de teoría y praxis, razón y emoción, ética y estética... Volveremos sobre el servicio que presta el artista a una sociedad libre, pero conste que esta lectura práctica de lo bello en nada instrumentaliza su gratuidad, sino que simplemente lo ofrece a todos como estímulo y alimento. La experiencia de la belleza es entonces uno de los caminos privilegiados que une a los hombres y les hace comprender sus derechos, despertando una sensibilidad dormida o alienada.

Este énfasis en lo mejor de la naturaleza humana - sus íntimos impulsos hacia la rebeldía, la libertad y la belleza- es el sustento de la confianza, pero urge concretarla en una fuerza activa que vierta esos dones en la historia, de manera que es preciso contar con algún tipo de agentes reales que ayuden a mejorarla. Pues bien, el protagonismo no recae en un pueblo o raza superior, en una clase social o en dirigentes providenciales, sino que la esperanza de cambio «la despiertan, la reaniman y la mantienen millones de solitarios, cuyas obras y acciones niegan cada día las fronteras y las más burdas apariencias de la historia, para hacer resplandecer fugitivamente la verdad siempre amenazada que cada uno, por encima de sus sufrimientos y alegrías, eleva para todos» (ibid., V-191). No hay portadores de la salvación y menos aún debe confiarse en grupos organizados que la prometan y monopolicen en detrimento de otros. Por eso el escritor francés se refugia en los seres anónimos ajenos a una disciplina impuesta, los $s o-$ litarios - figura diferenciada también de las masas y de las élites - que rechazan los compartimentos nacionales, ideológicos, religiosos, etc., aquellos que aportan con su quehacer diario honestidad y respeto al conjunto social del que forman parte. Ese tejido intrahistórico y transversal constituido por cada uno de esos individuos libres contribuye a depurar las obsesiones excluyentes, de modo que fomentan la aparición de instituciones más acordes con la vida buena, alejadas por igual del comunitarismo y del individualismo unilaterales.

Echamos en falta, no obstante, una definición clara y todo resulta bastante vago, entre otras cosas porque Camus no es un teórico y tampoco ve una alternativa clara en su tiempo, pero la intención es diáfana: optar por esa humanidad silenciosa frente a los desvaríos militantes es romper con la rigidez de los grupos cerrados y apelar al ciudadano de a pie que tiende puentes y juega limpio con los demás. Cabe suponer, además, que esa población de solitarios solidarios encajaría con lo que hoy se denomina la sociedad civil (aunque el término esté viciado por un liberalismo sesgado) y con el embrión de la comunicación en red contemporánea, multicultural y más tolerante, o con quienes se organizan en ONG's y otras asociaciones similares (defensores de las minorías, feministas, ecologistas, etc.). Es muy difícil crear nuevos sujetos históricos y articular alternativas políticas eficaces, entonces y ahora, pero nos parece que Camus estaría encantado de aprovechar las ventajas tecnológicas y de acción que ofrece el presente para caminar en esa línea. Sin olvidar la propuesta de una ciudadanía universal que supere el tribalismo en sus diversas manifestaciones (como bien sabía quien estaba desgarrado entre su condición de africano y de europeo), un reconocimiento de derechos y deberes a su vez orientado por el respeto a la diferencia pero obligado a la semejanza. De ahí que propusiera - antes de la creación de la ONU - una «organización mundial» para preservar la paz, fundada en un nuevo «contrato social» de las estructuras intermedias de las sociedades así como en una serie de valores fundamentales 
(Crónicas 1944-1948, II-720 ss.). Necesidad vigente, por supuesto, no solo a la vista de las insuficiencias observadas en los organismos internacionales, sino de las aporías y conflictos que no tienen solución, como bien sabía el escritor de primera mano. Así la famosa frase donde afirmaba que elegiría a su madre antes que a cualquier doctrina o país deja zanjado el asunto a favor de la apuesta reiterada por el factor humano, aún más justificada si cabe en los callejones sin salida aparente.

El mensaje último es sencillo: a la postre, hay que confiar en la buena voluntad de las personas, especialmente cuando se unen para conseguir lo que consideran justo. Claro que cualquier cambio es limitado e insatisfactorio - la lógica política contemporánea no admite revoluciones - y que las fuerzas contrarias a una redistribución del poder o la riqueza son poderosísimas, como vemos todos los días, pero nuestro autor ha enseñado que ése es el punto de partida ya asumido, no el de llegada. Por último, no está de más recuperar la apuesta inicial de Camus por la figura de Prometeo, el héroe encadenado que mantiene con «prolongada obstinación» la memoria de libertad y belleza de la que no podemos prescindir, con su «tranquila fe en el hombre (...) Y esa admirable voluntad de no descartar ni excluir nada de cuanto siempre ha reconciliado y aún reconciliará el corazón dolorido de los hombres con las primaveras del mundo» (El verano, III-562). Más allá de la desdicha, queda la fuerza recóndita y la perseverancia de quienes no olvidan ni renuncian, aunque sea guiados por ilusiones personales que alimentan el posibilismo o el «como si» mencionado al principio de estas páginas. Las experiencias alegres en las que apoyarse y la resolución de buscar siempre una vía para seguir adelante son la base sobre la que obliga- ción y convicción se dan la mano para ser fieles a Prometeo, es decir, a uno mismo.

\section{Contrastes y similitudes: ayer y hoy}

No hay recetas ni transposiciones fáciles, ya se advirtió, y tenemos más elementos de crítica que de alternativa consistente. Pero eso tampoco debe amordazar el discurso rebelde, ya de por sí desvaído en las últimas décadas, ni aunque se viera obligado a perseguir solo el mal menor. Por de pronto, el ejemplo vital de Camus no pierde fuerza a pesar de sus dosis de voluntarismo, pues se trata de alguien coherente en su lucha que nunca dijo tener la panacea. Retomamos la lucidez de su compromiso como estímulo ante la expectativa de que vuelvan polarizaciones y conflictos que parecían un tanto superados, tanto políticos como económicos. De hecho, su diagnóstico de fondo se refiere a la existencia de un grave «problema de civilización» presentado en los términos de un dilema aún vigente: ser capaces o no de crear nuevos valores (que no dependan de la supuesta ayuda de lo eterno ni del racionalismo historicista) nada menos que para poder sobrevivir (Crónicas 1944-1948, II-684). Hagamos un pequeño examen de la cuestión, aunque no parece que los valores hoy triunfantes de la ganancia y la seguridad a ultranza hayan dado buen resultado.

Sin convertir al autor en un profeta, es útil analizar de su mano algunas cosas. Por ejemplo, la vuelta al estatalismo más rudo: «Graves doctores meditan a diario sobre la decadencia de nuestra sociedad buscando las razones profundas. Esas razones existen, sin duda. Pero para la gente sencilla, el mal de la época se define por sus efectos, no por sus causas. Se llama Estado, policial o burocrático. Su 
proliferación en todos los países, bajo los más diversos pretextos ideológicos, la insultante seguridad que le dan los medios mecánicos y psicológicos de la represión, lo convierten en un peligro mortal para lo mejor que existe en cada uno de nosotros» (ibid., II-770). Este diagnóstico parece hoy excesivo, pero diferentes amenazas reales o ficticias han sido instrumentalizadas en esa dirección, como sabemos. A la vez, paradójicamente, salvo en las cuestiones militares y de orden público, se da una demolición desde dentro del Estado en su vertiente generadora de bienestar y protección social, mientras que sufre desde fuera el desbordamiento de una globalización incapaz de formar estructuras supranacionales solventes. Parece haber, en fin, una situación confusa e indefinida de retraimiento nacionalista y cobardía, que en nada ayuda a resolver los problemas.

De ahí que tengamos la tentación de coincidir con el escritor en que la sociedad política contemporánea es «repugnante», aunque haya mejorado desde la postguerra, porque sigue siendo una «máquina de desesperar a los hombres» ante la que no cabe otra ética que «atestiguar y clamar, cada vez que sea posible, y en la medida de nuestro talento, a favor de los que están sojuzgados como nosotros» (ibid., II-774). La desesperación actual no proviene de la tiranía a gran escala y del sectarismo ideológico, sino de haber obtenido unas ventajas legales y materiales que adormecieron la conciencia crítica con la promesa de otra clase de paraíso (en el Primer Mundo) ligado al consumo en vez de a la política, mientras que ahora esos beneficios se pierden bruscamente. La gran crisis económica de los países ricos (no se olvide) es la consecuencia de un éxito inicial preñado de corrupción al abandonarse todo una vez más en manos de ídolos que postergan a las personas. Y lo peor es que además puede marcar el curso social de los acontecimientos para el resto del planeta, con independencia del mayor o menor incremento del PIB.

En medio de los sueños rotos (bastante mediocres a veces y cómplices con los abusos cometidos sobre terceros), crece el descontento y la desigualdad hasta el punto de que no sería extraño que surjan tensiones mayores. Es probable que los problemas (pérdida de derechos y desempleo, pobreza y xenofobia, medidas coercitivas crecientes en última instancia para defender los intereses de los privilegiados...) conduzcan de nuevo a un estado más policial y burocrático. De hecho, ya se ha preparado el terreno al hilo de la llamada «guerra contra el terror», como evidencia la legitimación de la tortura y del control de las comunicaciones, la suspensión en algunos casos del hábeas corpus, los controles y vigilancia abusivos de personas y fronteras, etc. Las líneas de fuerza económicas y políticas parecen converger así peligrosamente hacia la coerción, por más que sus contenidos concretos difieran obviamente de los que vivió Camus. Los retrocesos materiales, morales y jurídicos de los últimos tiempos están a la vista, pero no parece que el terrorismo islamista o de otra índole sea peor que los terrorismos de Estado, ni que la lucha feroz de los menos favorecidos entre sí para no quedar fuera del reparto cada vez menor de bienes y servicios sea un futuro deseable, por solo citar dos aspectos.

Es claro que esta crisis de civilización venía de lejos y ya ha sido glosada por muchos, a veces en exceso y con siniestro afán apocalíptico. Pero entre ellos no estaba Camus, quien describe con pinceladas agudas el curso que tomaban las cosas: la «sociedad de los comerciantes» escamotea las realidades «en beneficio de los signos», y una sociedad basada en los signos es tan artifi- 
cial que mixtifica «la verdad carnal del hombre», cubriendo las cacareadas ideas de libertad e igualdad con un barniz formal que da cobertura a la opresión subyacente (Conferencia de Upsala, V176s.). Este proceso que podría definirse como el sometimiento de lo vivo a lo abstracto es parejo a la rendición definitiva de la política ante el dinero, e incluso anuncia la desmaterialización gradual del mundo generada por la alianza de las finanzas y la tecnología (es sabido que los signos y el capital ya son digitales). De donde resulta que la existencia humana se volatiliza bajo el peso abrumador de lo ficticio y de lo virtual que hoy aplasta aún más la carnalidad de la vida. ${ }^{17}$ A lo que se añade, en segundo lugar según Camus, el imperio de la fama, del ruido y del espectáculo, en el que las protestas y el malditismo son unos ingredientes más del show, incluido el papel inane de los artistas sometidos a las modas. La consecuencia es que, «Naturalmente, la sociedad actual, fatigada o indiferente, no aplaude o silba mas que por azar» (ibid., V-179). La frivolidad es entonces el correlato idóneo que enmascara la deshumanización, podríamos concluir, ambas cosas bien trabadas en el infantil exhibicionismo de nuestra época, sea de riqueza, de poder o de éxito. Según el tópico, lo que no es visible no existe y carece de valor, o viene dictado solo por el dinero y la imagen...

Qué se puede hacer entonces, a la luz de los textos referidos, en una sociedad que presume de no creer en nada que no sea tangible y a la vez se abalanza sobre cualquier creencia de saldo que ofrezca alguna seguridad. Haríamos mal en adjudicar a Camus un afán moralizante y una especie de repliegue disgustado a la soledad egregia en tiempos de tribulación, pues el francés siempre prefiere implicarse y mancharse las manos. En este sentido hay que entender que elija lo «espiritual» frente a lo «moral», con distintos enfoques a lo largo de su vida, y que no renuncie a una felicidad nunca exenta de belleza y dolor, pero siempre incompatible con el juicio severo que se impone desde fuera del ser (véanse p. ej. I-108s. y V-421s.). En él no encontraremos a un predicador adusto ni a un optimista vendedor de humo, sencillamente porque sabe que nada es fácil o simple, por lo mismo que tampoco cayó en una red de doctrinas o códigos y mucho menos en la trampa de verse por encima de los acontecimientos. Su enseñanza es relativamente llana y nace de la experiencia literaria e histórica: solo queda aferrarse - como hace el auténtico artista- a un amor sincero por el prójimo que nada tiene de «catecismo de tribunal», apelar al esfuerzo y el coraje que acompañan a la imprescindible «voluntad de clarividencia», al empeño de equilibrar la libertad y la justicia, así como a la memoria y el riesgo inherentes a una sabiduría que se «enfrenta por fin a peligros reales»(Conferencia de Suecia, V-187, 188, 189 y 190, respect.). Nada más y nada menos, algo casi intuitivo que no hace falta explicar. Un hombre al que H. Arendt definió alguna vez como el más justo de Francia, sin militancia en una causa partidista para poder hacerlo en las que consideraba esenciales, navegando con valor entre la autonomía y la heteronomía que a todos conciernen..., ésa es la huella que deja.

Queda un último apunte para ofrecer un poco más de sentido e intentar unir a los hombres en torno a él, «como si» hubiera un futuro mejor que lo conocido hasta ahora. Camus remite siempre a la comunidad de lo humano y queda ya constancia del papel decisivo que juegan la dignidad y la libertad compartidas, pero es momento de añadir algunas notas que matizan esas nociones. Por ejemplo, «la amistad es la ciencia de los hombres 
libres. Y no hay libertad sin inteligencia y sin comprensión recíprocas» (Crónicas 1944-1948, II-689). La apertura hacia el otro y el entendimiento amable enriquecen ese núcleo de lo humano que a todos constituye, como enseña la mejor tradición filosófica a la que nuestro autor se suma: para el sabio es mucho más importante comprender que condenar y la amistad es el mejor fruto de la vida intersubjetiva. No es preciso repetir las palabras memorables de Aristóteles, Epicuro o Spinoza al respecto, baste con apuntar que si esa actitud interior es cultivada por muchos seres humanos que confían amigablemente en otros (lo que no significa ser demasiado confiado pero sí arriesgarse), ello incidirá en la disposición general con que se afronten los peligros que se avecinan y solo desde ahí podrá construirse el movimiento cívico y político que hace falta para ello.

Cultivar esas cualidades en cada uno, antes de llegar a la institucionalización del tipo que sea, es la tarea previa a realizar sin perderse en generalidades o buenas intenciones. Hace falta voluntad y conocimiento, ejercitarse mucho y colaborar con otros asiduamente, cierto, pero antes hay que atender realidades y emociones nada triviales que están al alcance de cualquiera si uno repara en ello: «es necesario hablar de lo que todos conocen y de la realidad que nos es común. El mar, la lluvia, la necesidad, el deseo, la lucha contra la muerte, eso es lo que nos reúne a todos. Nos reunimos en lo que vemos juntos, en lo que conjuntamente sufrimos. Los sueños cambian con los hombres, pero la realidad del mundo es nuestra patria común» (Conferencia de Suecia, V-180). Superar tantas resistencias y conflictos, incluso la falta de proyectos comunes, exige salir de las diferentes identidades simbólicas y coincidir en lo que está fuera pero atañe a todos, es decir, hay que ocuparse de esa «patria común» donde convergen el entorno y ciertas constantes de la vida. Esta especie de rodeo por la objetividad del mundo es la vía certera para llegar a lo más íntimo del hombre, pues en ese espejo nos vemos reflejados y es el ámbito donde alienta la existencia de todos. El tránsito de las diferencias histórico-culturales a lo natural básico (el paisaje, la muerte...) permite acercarse y dejar en segundo plano lo que separa, toda vez que el mínimo común denominador de la vida (en aspectos externos e internos) tiene un sesgo orgánico y otro ecológico, entendidos ambos de modo inclusivo y no reduccionista. Todos necesitamos la lluvia o alimentar la carne que somos, sin ir más lejos, y de esa matriz surge precisamente la espiritualidad y la concordia, pues en ello nos reconocemos iguales y a partir de ahí crece la conciencia. Cuando esos equilibrios eco-bio-antropológicos se trastocan en demasía, como ocurre hoy, algo grave amenaza - en sentido objetivo y subjetivo- a la extraña especie del sapiens-demens que habita este pequeño planeta con las demás.

Camus no tiene las mismas preocupaciones que nosotros, pero sí alude al trasfondo cultural y ético de donde surgirán bastantes andando el tiempo. De ahí el interés que guarda para el presente recuperar lo que llama «ley de la mesura», entendida en una línea clásica como el intento de mediación entre lo racional y lo irracional, el sentido y el sinsentido, esencia y existencia, ser y devenir, vida y valores, individuo y sociedad... ( $E l$ hombre rebelde, III-336 a 346), con la pretensión de conciliarlos siquiera un poco desde la flexibilidad interna y la tolerancia colectiva. Pues bien, digamos que estas polaridades perennes tienen un cariz intensional (casi metafísico) que bien puede completarse con otro extensional (más físico e histórico), que tematiza en sus escritos: el empeño por inte- 
grar mundo y hombre, lo natural y lo cultural, lo propio y lo ajeno... Son las dos caras de la existencia y ambas resultan imprescindibles, como lo son los llamados valores de la vida y los de la libertad, de manera que semejante intento de relacionar (logos) característico de la alianza de inteligencia y sensibilidad debería llamarse hoy pensamiento global, incluida su insoslayable lectura política. Acaso esta lucha perpetua contra los dualismos y las escisiones, aun sabiéndose en gran parte perdida, constituya la tarea que ningún pensador debe abandonar, especialmente en tiempos difíciles... como lo son casi todos. Camus lo sabía bien, por eso nos sirve aún de inspiración.

\section{BIBLIOGRAFÍA}

Arendt, H.: ¿Qué es la política?, Barcelona, Paidós-UAB, 1997.

Camus, A.: Obras, ed. a cargo de J. M. ${ }^{a}$ Guelbenzu, Madrid, Alianza, 5 volúmenes, 1996.

Del Águila, R.: La senda del mal. Politica y razón de estado, Madrid, Taurus, 2000.

Espinosa Rubio, L.: «El humanismo de Albert Camus», en Colectivo: Filosofia y literatura, Sociedad Castellano-
Leonesa de Filosofía, Salamanca, 2000, pp. 43-67.

Espinosa Rubio, L.: «El desafío del posthumanismo. En relación a la nuevas tecnologías», en Aullón, P. (ed.): Teoría del humanismo, Madrid, Verbum, vol. III, 2010, pp.583-615.

Espinosa Rubio, L.: «El nihilismo virtual en la sociedad hipertecnológica», Ágora 26/2 (2007) 79-101.

Griffin, R.: Modernismo y fascismo. La sensación de comienzo bajo Mussolini y Hitler, Madrid, Akal, 2010.

Hegel, G. W.: Fenomenología del espíritu, Madrid, FCE, 1982.

Maalouf, A.: El desajuste del mundo. Cuando nuestras civilizaciones se agotan, Madrid, Alianza, 2009.

Onfray, M.: Tratado de ateología. Física de la metafísica, Barcelona, Anagrama, 2006.

Rodríguez Duplá, L.: Ética de la vida buena, Bilbao, Desclée, 2006.

Savater, F.: La vida eterna, Barcelona, Ariel, 2007.

Serrano, V.: La herida de Spinoza. Felicidad y política en la vida postmoderna, Barcelona, Anagrama, 2011.

Todd, O.: Albert Camus. Una vida, Barcelona, Tusquets, 1997.

Welzer, H.: Guerras climáticas. Por qué mataremos (y nos matarán) en el siglo XXI, Madrid-Buenos Aires, Katz, 2010.

NOTAS

1 Sigo la edición en cinco volúmenes de Camus, A.: Obras, a cargo de J. M. ${ }^{\text {a }}$ Guelbenzu, Madrid, Alianza Tres, 1996. En adelante citaré en el texto el título del escrito, el volumen y la página, en este caso Carnets 3, V, 390.

${ }^{2} \mathrm{He}$ analizado esta cuestión por extenso en «El humanismo de Albert Camus», en el volumen colectivo Filosofia y literatura, Salamanca, Sociedad castellano-leonesa de filosofía, 2000, pp. 43-67. Ahí queda claro que el escritor se aleja por igual del humanismo burgués y del comunista, además de afirmar la simbiosis entre filosofía y literatura. Si entonces primaba el estudio de las obras de ficción, ahora abordaré sus ensayos y artículos.

${ }^{3}$ Cf. Savater, F.: La vida eterna, Barcelona, Ariel, 2007, pp. 167 ss.

${ }^{4}$ Sobre la importancia de ejercer el buen juicio político y social ante las peculiaridades históricas contemporáneas (totalitarismos, peligro nuclear), donde ya no sirven las referencias anteriores, cf. Arendt, H.: 
¿Qué es la politica?, Barcelona, Paidós-UAB, 1997, pp. 61 ss.

${ }^{5}$ En palabras de M. Onfray: «La credulidad de los hombres sobrepasa lo imaginable. Su deseo de no ver la realidad, sus ansias de un espectáculo alegre, aun cuando provenga de la más absoluta de las ficciones, y su voluntad de ceguera no tiene límites. Son preferibles las fábulas, las ficciones, los mitos, los cuentos para niños, a afrontar el desvelamiento de la crueldad de lo real que obliga a soportar la evidencia de la tragedia del mundo», en Tratado de ateología. Física de la metafísica, Barcelona, Anagrama, 2006, p 22.

${ }^{6}$ Remitimos a la excelente biografía de Todd, O.: Albert Camus. Una vida, Barcelona, Tusquets, 1997.

${ }^{7}$ Cf. Maalouf, A.: El desajuste del mundo. Cuando nuestras civilizaciones se agotan, Madrid, Alianza, 2009, pp.189 y 269. El escritor franco-libanés, al igual que Camus con doble raíz cultural, combate lo que llama las identidades asesinas y apuesta por la universalidad de los valores esenciales que adquieren diversa expresión cultural, cf. p. 276.

${ }^{8}$ Movimientos que a mi juicio proponen una lista de reclamaciones básicas para conservar lo mejor de una sociedad civilizada y después convertirla en algo más decente, sin radicalismo alguno.

${ }^{9}$ Cf. del Águila, R.: La senda del mal. Politica y razón de estado, Madrid, Taurus, 2000, cap.3.

${ }^{10} \mathrm{Cf}$. el interesante comentario al respecto, tomando como hilo argumental la obra de Camus Los justos
(1949), de Rodríguez Duplá, L.: Ética de la vida buena, Bilbao, Desclée De Brouwer, 2006, cap. 8.

${ }^{11}$ Cf. Hegel: Fenomenología del espíritu, Madrid, FCE, 1982 (5. reimp.), p. 55.

${ }^{12}$ Cf. Serrano, V.: La herida de Spinoza. Felicidad $y$ política en la vida postmoderna, Barcelona, Anagrama, 2011, pp. 39s., 57ss., 118, 121. Tener en cuenta lo natural y establecer unos Derechos Humanos universales responde al intento defensivo de poner algunos límites, sostiene también el autor citado.

${ }^{13} \mathrm{Cf}$. Mi artículo «El desafío del posthumanismo. En relación a las nuevas tecnologías», en Aullón, P. (Ed.): Teoría del humanismo, Madrid, Verbum, 2010, vol. III, pp. 583-615.

${ }^{14}$ Cf. Griffin, R.: Modernismo y fascismo. La sensación de comienzo bajo Mussolini y Hitler, Madrid, Akal, 2010. Es interesante notar que Camus - como en esta obra se indica- reconoce en las Cartas que la cultura occidental se dejó influir demasiado por esa creencia en la refundación de una Modernidad supuestamente fracasada.

${ }^{15} \mathrm{Cf}$. los instructivos y documentados análisis de Welzer, H.: Guerras climáticas. Por qué mataremos (y nos matarán) en el siglo XXI, Buenos Aires, Katz, 2010.

${ }^{16}$ Lo que recuerda la noción budista de avidya o ignorancia sufriente que estriba en un profundo error de percepción.

${ }^{17}$ Cf. mi trabajo «El nihilismo virtual en la sociedad hipertecnológica», Ágora 26/2 (2007) 79-101. 